\title{
Reseña
}

\section{Fernando Velázquez Velázquez, Fundamentos de Derecho Penal. Parte General, Bogotá, Tirant lo Blanch, 2020, 957 páginas.}

Roberto Cruz Palmera* 
Se encuentra el lector ante un manual solvente que aborda un análisis de la parte general del derecho penal. Esta nueva edición ha sido publicada por la prestigiosa editorial jurídica internacional Tirant lo Blanch, bajo el título Fundamentos de Derecho Penal. Parte General. Esta contribución, como se adelantó, examina de manera integral los elementos que componen el estudio de la teoría jurídica del delito.

El trabajo del profesor Fernando Velásquez se estructura en una nota introductoria, veinticuatro capítulos y una bibliografía general; además de la bibliografía, el autor nos proporciona en el capítulo veinticuatro una guía para la solución de casos prácticos e instrucciones para analizar providencias judiciales.

Este manual podría dividirse en tres partes. En la primera parte, su autor abarca de forma genérica el derecho penal, en donde analiza, entre otros temas, la dogmática penal y los saberes penales, los límites del derecho penal subjetivo, los principios rectores del derecho penal, la norma penal y sus fuentes, así como la historia del derecho penal (caps. 1-8). Destaca en este apartado el concepto de dogmática penal adoptado por el autor. Sobre el particular afirma que:

... es el saber que estudia el derecho penal positivo, que averigua el contenido, los presupuestos y las consecuencias de las normas punitivas, las que desarrolla y explica en su conexión interna; que ordena el material jurídico en un sistema, en el cual tiene cabida las elaboraciones de los tribunales y de la doctrina, e intenta, en fin, hallar nuevos caminos de desarrollo conceptual y sistemático. (p. 11)

En la segunda parte, el profesor Velásquez desarrolla el concepto de Delito, analizando varios tópicos como las bases de la teoría del delito, la conducta, la tipicidad en la conducta comisiva dolosa, la antijuridicidad, la culpabilidad, la tentativa y el concurso de personas (Caps. 9-17). Se subraya en este apartado el concepto de dolo reseñado por el autor. $\mathrm{Al}$ respecto, tras una impecable explicación normativa afirma que:

El primer momento del dolo, esto es, el intelectual, comprende no solo el conocimiento de las circunstancias del hecho, sino también la previsión del desarrollo del suceso mismo incluidas la imputación objetiva y el resultado, esto es, lo que la ley denomina "los hechos constitutivos de la infracción penal" (art. 22). En efecto, cuando actúa, el agente debe conocer los elementos que compone la figura típica, de la misma manera que lo haría un hombre medio en su situación, ser consciente de ellas y considerar la producción de esas circunstancias como realmente posibles en el caso concreto, esto en cuanto al primer aspecto; sobre el segundo, es además indispensable tener conciencia de que la propia acción está en posibilidad de realizar el aspecto objetivo del tipo. [...] Como no basta con el conocimiento de los hechos constitutivos de la infracción penal (aspecto objetivo del tipo) y con la previsión del desarrollo del suceso, es indispensable, además, que el agente se decida a realizar la conducta tipificada; por ello se exige un segundo momento en dolo, denominado también voluntario, voluntativo e, incluso, conativo. (pp. 389 y 391) 
En la tercera parte se revisan con cierta profundidad las "Consecuencias jurídicas del Delito". Se estudian en este apartado la pena, la medida de seguridad, la determinación de la sanción, las causas de extensión de la pretensión punitiva del Estado y la responsabilidad civil derivada del delito (caps. 1824). Destaca en este apartado la noción sobre la pena que adopta el autor. Al respecto, afirma:

La pena es un mal dispuesto por el legislador para quien cometa un delito; y que, desde un punto de vista material, ella es objeto, de dilatadas discusiones en torno a su fundamento, justificación, sentido y fin [...]. Sin duda alguna, la pena es la privación o restricción de bienes jurídicos impuesta por el órgano jurisdiccional competente a la persona que ha realizado una conducta punible, acorde con las pautas legales correspondientes; tarea básica de la pena es la protección de los bienes jurídicos, para asegurar la coexistencia humana en sociedad. (pp. 660-661)

Hasta este punto el planteamiento trazado por el profesor Fernando Velásquez Velásquez.

Disfruté con un libro que da cuenta de todas las instituciones que un penalista debe estudiar y consultar con frecuencia, por citar solo algunas: la conducta humana, la tipicidad, la antijuridicidad, la culpabilidad, el concurso de personas, la tentativa, la legítima defensa. Ahora bien, pese a la calidad del libro y a la rigurosidad con que se abordan los temas, no pude dejar de disentir del criterio de selección y desarrollo de algunas instituciones que son analizadas de forma sucinta o escasa, es el caso de la doctrina de la imputación objetiva. En similar dirección, se detectan algunas imprecisiones terminológicas que deberían revisarse. Me refiero a valoraciones emitidas por el autor en el marco de la tipicidad. Al respecto, Velásquez Velásquez considera que la tipicidad es un indicio de la antijuridicidad. Pongo al lector en contexto:

No cabe duda en el sentido de que las causales de justificación son normas permisi-
vas, lo que se infiere del hecho de que el ordenamiento legal no solo consagra pro-
hibiciones y mandatos, sino también autorizaciones para actuar; es así como puede
afirmarse que los tipos penales contienen reglas generales que encuentran sus excepcio-
nes en las causales de justificación (sistema de regla-excepción), constituyéndose de
tal modo la tipicidad en un indicio de antijuridicidad, en su ratio cognoscendi. (p. 466)

Pasaré a argumentar brevemente el porqué de esta impresión en el ámbito de la tipicidad como categoría que compone el concepto del delito. No toda situación en la que la sociedad no censura la intromisión de intereses jurídicos de terceros se encuentra prevista en un tipo permisivo; sabemos que únicamente las situaciones más habituales -y por tanto tipificables- son las que llegan a convertirse en causas de justificación (o normas facultativas). Ahora bien, si esto es así, no es posible sostener que el tipo penal -facultativo o prohibitivo- se convierta o, más bien, represente un indicio de antijuridicidad como señala Velásquez Velásquez. Esto sí ocurre cuando se determina de manera 
objetiva una lesión a un bien jurídico. Ante dicha circunstancia, o sea, ante la lesión de un bien jurídico determinado, sí nos aproximamos a un indicio de antijuridicidad; dicho de otra manera, "sospechamos" que la conducta es antijurídica a no ser que se constate ex post una norma que la faculte (causa de justificación en particular). En ese orden, puede que el indicio de la antijuridicidad lo hallemos en la lesión de los intereses jurídicos protegidos, es decir, en la muerte de otro, en la apropiación de la cosa mueble ajena, en la destrucción de la $\cos a$; pero nunca en la tipicidad.

Sin menoscabo de lo anterior, el escrupuloso trabajo del profesor Velásquez Velásquez, expuesto ligeramente en tan breves páginas, nos proporciona una valiosa herramienta para el estudio de la parte general del derecho penal y nos ofrece interesantes propuestas de reflexión y análisis. Para cerrar, se trata de una obra con un indudable valor e interés teórico que sigue siendo clave para enriquecer el debate científico de nuestra materia. 